Cycad, Macrozamia spiralis. He has found urease also in the seeds of Abrus precatorius."

The earlier experiments referred to were my own. Mr. Benjamin had assisted Mr. Horton and me in our work on urease, published early in I9I3. He was a young Australian and he undertook the observations, on his return, at my request. When in Java, in September rgr4, I had the opportunity, at the Buitenzorg gardens, of testing fresh Abrus seeds and of confirming Benjamin's result. I may say, the amount present is small, in no way comparable with that in Soja beans.

To me the presence of urease in the nodules is little short of a matter of course-in view of their "ammonicity." The interest of the observation lies in the possible application thereof.

Urea is foreshadowed as the nitrogenous fertiliser of the future but apparently it has its limitations. All soils, all plants, do not respond to it equally. I was told years ago, that it is particularly good for Pease. Why, Mr. Peasecod? Probably it is not operative as such but merely as a source of ammonia and must be hydrolysed to make it available. Only soils which contain urease would respond. A cloversick soil may well be wanting in the organisms which give rise to the nodular growths.

To be practical--it would seem to be desirable to test the comparative effect of urea on the growth of non-leguminous plants when grown with and without a leguminous plant, such as clover.

$$
\text { Henry E. Armstrong. }
$$

\section{Colour Vision and Colour Vision Theories.}

In the first of my two recent letters on this subject I selected five of the cases in which Dr. EdridgeGreen asserts that the trichromatic theory cannot explain certain phenomena of colour vision; and I indicated, in each case, the source of his error. In more than one case I gave the full proof. In his reply he took no notice of these proofs except in so far as he seemed to admit their accuracy. But he brought forward three other cases, asserting incompetence of the trichromatic theory in connexion with them. In my second letter (NATURE, September 8) I similarly indicated the oversight involved in each of these three additional assertions.

I must confess, therefore, to some degree of surprise that Dr. Edridge-Green, in his letter appearing in NATURE of September 29, should say that he will deal with my explanations regarding the competence of the trichromatic theory when I give them. They are already given, and I shall be glad if he will discuss them. To make the matter definite, I invite him to discuss the trichromatic explanation which $I$ have given, in my first letter, of the case of so-called redblindness with shortening of the spectrum at the red end. The proof is fully given. Another proof, fully given in geometrical terms, is that dealing with the possible diminution of colour sensitiveness by the annulment of one component sensation.

Instead of discussing any of the eight explanations which I have already given either in full or in outline, Dr. Edridge-Green now points out that he is not alone in regarding the trichromatic theory as inadequate. Unfortunately, misunderstanding of the theory is too regrettably widespread for the reason which I expressed in my first letter. If any reader who is interested in the matter will refer to the discussion which I have given in my book he may recognise that the statement referred to in Dr. Edridge-Green's last letter, concerning contrast and colour blindness, is not correct. It cannot be discussed in the scope of a short letter.

I appreciate Prof. Frank Allen's work greatly.

$$
\text { No. } 28 \text { I } 7 \text {, VOL. I I } 2]
$$

The difficulty to which he refers vanishes, as I am sure he will readily recognise, when the three variables (threshold values) descriptive of non-external action are considered. In fact, in the whole field of contrast, after-images, recurrent images, and inhibition, the trichromatic theory has at its disposal a double set, not a single set, of three variables. Such work as that of Prof. Frank Allen is of great importance in view of the need of a formulation of the threshold values as functions of precedent illumination, time, secondary stimuli, etc. His early work, long ago, led $m e$, in attempting something different, to full recognition of the sufficiency of the trichromatic theory.

What blindness must have oppressed the mental vision of Helmholtz, "that investigator, worthy of wonder, leaping before his time," if it were true, as Dr. Edridge-Green asserts, that "There is no fact that directly supports the trichromatic theory." Which Helmholtz elaborated so as to fit facts, and used victoriously to predict others! I know of none that fails to support it. I have studied Dr. EdridgeGreen's book very carefully, and I have not found one of his strictures upon the theory with which it was possible to agree. Even Sir William Abney, one of the supporters of the theory, whose experimental work was so admirable, was led to some wrong conclusions through non-perception of some of its possibilities.

Dundee, September 29.

W. PEDdrE.

\section{Sexual Physiology.}

IN NATURE of September I, p. 3I7, under the heading " Sexual Physiology," a review appeared of the second edition of Dr. Marshall's book "The Physiology of Reproduction." In the course of this notice certain misleading statements are made regarding myself. The reviewer, in referring to the chapter of the work dealing with the subject of the fertilisation of the ovum, states, "The least satisfactory part of the book, both as regards arrangement and subjectmatter, is, we think, that contributed by Dr. Cresswell Shearer on fertilisation."

May I point out that I am not the author of this chapter; while I have revised Dr. Marshall's manuscript, and added a number of notes here and there of minor importance, the two sections of which I am the author are clearly indicated in the footnotes, and I think are sufficiently obvious. In regard to that part of the chapter which has called forth the special criticism of the reviewer, "The hereditary effects of fertilisation," I am altogether unresponsible, although I completely agree with many of the opinions expressed by Dr. Marshall in this section. As the whole of this paragraph appears almost unaltered in the old edition, it would seem that your reviewer is by no means as familiar with the original work as he would have us believe.

C. Shearer,

A Footnote to Chapter vi,, " Fertilisation," states that this has been "Revised, with numerous additions, by Cresswell Shearer." It was assumed, from this, that Dr. Shearer had taken the chapter as it stood in the first edition and had made himself responsible not only for the numerous additions but also for the whole of the subject-matter of this chapter in the present edition, and for its presentation. That we are not alone in reading this meaning into the footnote is shown by the fact that another reviewer, writing elsewhere, states that "Dr. Cresswell Shearer has written in this edition a most excellent chapter on fertilisation." If Dr. Shearer did revise the chapter, then his objections are but 